\title{
Facile Anomer-oriented Syntheses of 4-Methylumbelliferyl Sialic Acid Glycosides
}

\author{
Abdullah A. Hassan ${ }^{a}$ and Stefan Oscarson*a \\ ${ }^{a}$ Centre for Synthesis and Chemical Biology, University College Dublin, Belfield, Dublin, Ireland, \\ Email: stefan.oscarson@ucd.ie
}

\begin{abstract}
As part of a program to find new sialidases and determine their enzymatic specificity and catalytic activity, a library of 4-methylumbelliferyl sialic acid glycosides derivatised at the $\mathrm{C}-5$ position were prepared from $N$-acetylneuraminic acid. Both $\alpha$ - and $\beta$-4-methylumbelliferyl sialic acid glycosides were prepared in high yields and excellent stereoselectivity. Alpha anomers were accessed via reagent control by utilising additive $\mathrm{CH}_{3} \mathrm{CN}$ and TBAl, whereas the beta anomers were synthesised through a diastereoselective addition reaction of iodine and the aglycone to the corresponding glycal followed by reduction of the resulting 3-iodo compounds. Both anomer-oriented synthetic pathways allow for gram-scale stereoselective syntheses of the desired C-5 modified neuraminic acid derivatives for use as tools to quantify the enzymatic activity and substrate specificity of known sialidases, and potential detection and investigation of novel sialidases.
\end{abstract}

Keywords: Carbohydrate synthesis, stereoselective glycosylation, sialic acids, chemoenzymatic substrates

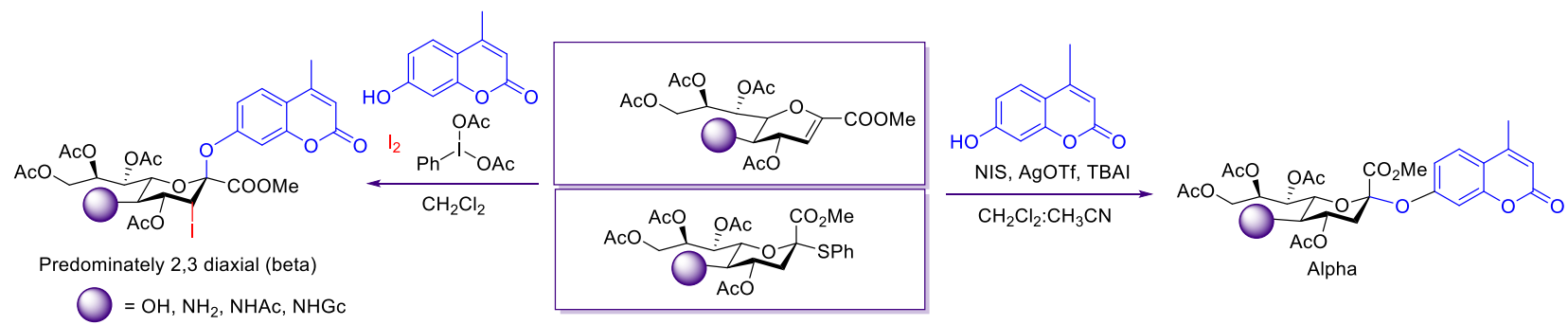




\section{Introduction}

Sialic acids are a family of nonulosonic acids that are found as terminal residues in a wide variety of mammalian and prokaryotic cell lines. As a result of their terminal position in glycoproteins and glycolipids, they have been shown to be implicated in numerous biologically important processes such as cellular recognition, signalling and adhesion. ${ }^{1}$ Their presence on cell surfaces are critical to normal cellular function in mammals. ${ }^{2}$ Similarly, in bacterial and viral species, sialic acids are vital components for pathogenesis and bacterial nutrition. ${ }^{3,4}$ In nature, there are currently over 80 differently modified members of the sialic acid family. As a starting point, we have selected to work on the most common C-5 modified sialic acid derivatives found in mammalian and bacterial cells (Figure 1). The exact biological consequence of these modifications is still an ongoing endeavour in glycobiology. ${ }^{5}$

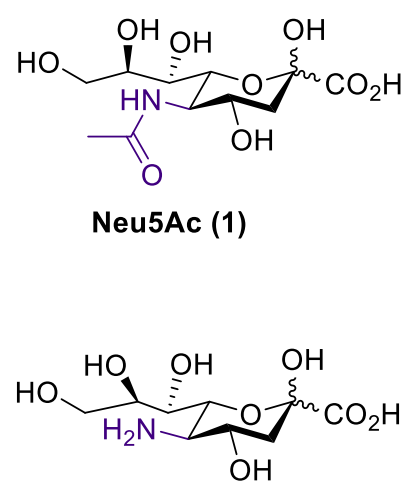

Neu (3)<smiles>CC(C)(C)[Mg]</smiles><smiles></smiles>

$\operatorname{Kdn}(4)$

Figure 1: Selected C-5 derivatised neuraminic acid derivatives found in nature

The amount of sialic residues incorporated into glycoconjugates within a given cell is typically regulated by the expression levels and activity of sialyltransferase and sialidase enzymes. ${ }^{6}$ While sialyltransferases catalyse the addition of sialic acid monomers to their corresponding glycoconjugate moieties, sialidases (also referred to as neuraminidases, EC 3.2.1.18) catalyse the cleavage of sialic acid residues from their component glycan and peptide chains.78 Consequently, sialidases have been shown to be critical components for a myriad of cellular phenomena such as modulation of protein recruitment, ${ }^{9}$ cell differentiation, ${ }^{10}$ cell signalling ${ }^{11}$ and apoptosis. ${ }^{12}$ Recently, Bertozzi and co-workers designed an $\alpha$ HER2 antibody-sialidase complex that selectively cleaves $\alpha$ linked sialoglycans from breast cancer cells in order to induce an immune response against breast cancer in mice. ${ }^{13}$

As the amount of sialic acid molecules incorporated into the cell is regulated by sialidase enzymes, methods to identify and quantify sialidase activity is of paramount interest. ${ }^{7}$ Generally, the hydrolytic activity of sialidases can be quantified by using synthetic fluorogenic substrates, such as 4-methylumbelliferylneuraminic acid, or other chromogenic or radiolabelled substrates. ${ }^{14-17}$ While the $\alpha$-4-methylumbelliferyl $N$-acetylneuraminic acid $(\mathbf{1 7} \alpha)$ is commercially available, the 
corresponding $\beta$ anomers (to probe the potential existence of $\beta$-sialidases) and common $C-5$ derivatives of sialic acid are not easily accessible. Additionally, the chemistry of 4methylumbelliferyl sialic glycosides has been left unexplored for many years despite existing synthetic routes suffering from poor yields, low stereoselectivity and formation of the undesired glycal side product. ${ }^{18-21}$ To this end, we report herein synthetic strategies to access C-5 derivatised neuraminic acid substrates with a fluorogenic 4-methylumbelliferyl (4-Mu) aglycone functionality in both anomeric configurations as tools to probe sialidase activity and specificity.

\section{Results and discussion}

Our syntheses starts from commercially available $N$-acetylneuraminic acid (1) (Scheme 1). The synthetic pathway is divided into two modular anomer-oriented approaches utilising glycal $\mathbf{5}$ and thiophenol 6 to stereoselectively install the fluorogenic aglycone at the anomeric position. Our previously developed $\mathrm{Phl}(\mathrm{OAc})_{2} / \mathrm{I}_{2}$ mediated diastereoselective olefin addition reaction would give rise to the $\beta$ anomers, ${ }^{22}$ while we envisioned that the $\alpha$ anomers could be obtained by utilising solvent control methodology previously investigated by others. ${ }^{23}$

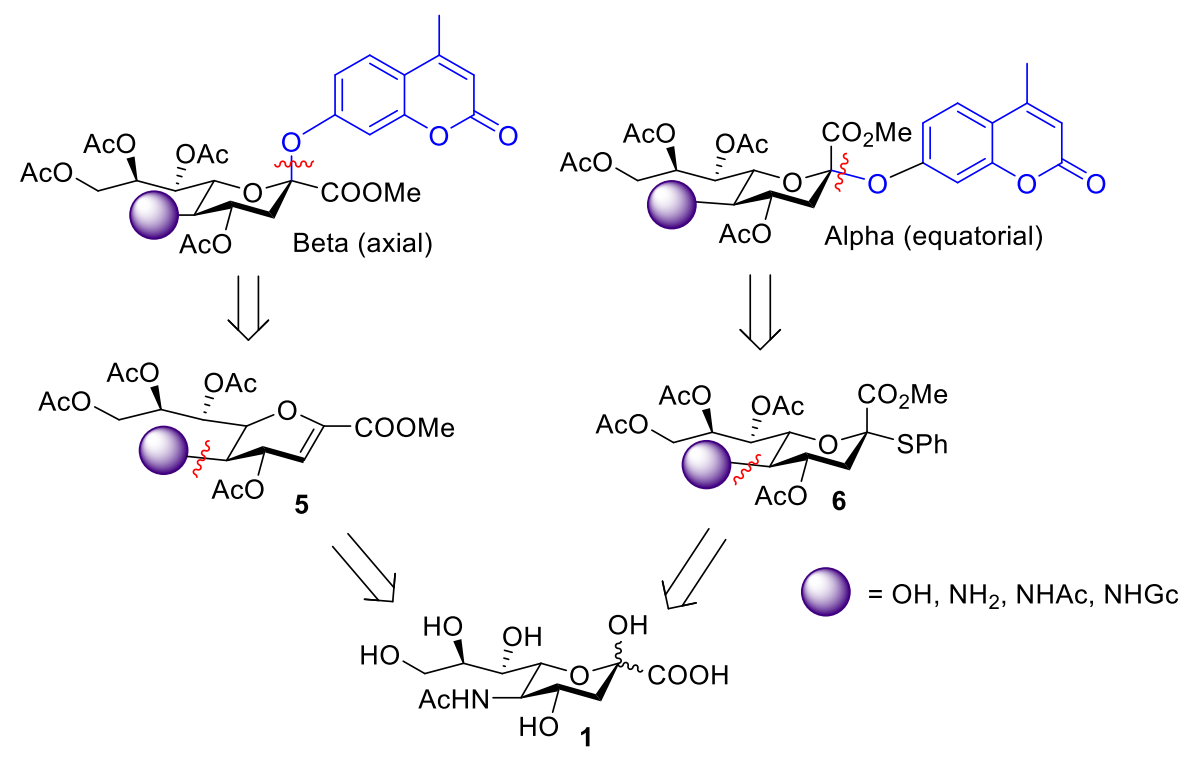

Scheme 1: Retrosynthetic analysis of C-5 derivatised sialic acid glycosides

Our synthesis towards the equatorial $\alpha$-glycosides of our desired C- 5 functionalised Neu5Ac derivatives began with preparation of the common Neu5Ac thiophenol donor 7, which was prepared in 2 steps from commercially available Neu5Ac. ${ }^{24}$ Initial efforts were then focused on derivatising this shared intermediate at the $\mathrm{C}-5$ position to subsequently introduce our requisite fluorogenic glycosides. Accordingly, we converted $\mathbf{7}$ into its corresponding $\mathrm{N}$-glycolyl neuraminic acid by condensation of free amine 8 with activated ester 9 in a mixture of $\mathrm{CH}_{3} \mathrm{CN}$ and water affording Neu5Gc thioglycoside 11 in 61\% yield over three steps. ${ }^{25}$ Simple replacement of the benzylated activated ester into its acetylated form $\mathbf{1 0}$ allowed for the gram scale synthesis of Neu5Gc donor 12 in 89\% yield over three steps (Scheme 2). Both donors were investigated to 
determine if the electronic differences in the glycolyl side chain affected the stereochemical outcome of the glycosylation reaction. Similarly, the free amine complex $\mathbf{8}$ was also treated with 2,2,2-trichloroethoxycarbonyl chloride (TrocCl) to chemoselectively mask the amine functionality. Acetylation of the Troc protected derivative gave Neu5Troc thioglycoside $\mathbf{1 3}$ in $\mathbf{7 8 \%}$ yield over three steps (Scheme 2). Next, using a modified oxidative deamination methodology originally developed by Zbiral ${ }^{26}$ and Ogura ${ }^{27}$, and later applied to thioglycosides by Crich et al. ${ }^{28}$, the requisite Kdn thiophenyl sialoside was prepared via treatment of $\mathbf{7}$ with nitrosonium tetrafluoroborate $\left(\mathrm{NOBF}_{4}\right)$ to furnish the corresponding nitrosyl amide intermediate $\mathbf{1 4}$ in an almost quantitative yield (Scheme 2). Subsequent stepwise addition of sodium isopropoxide, trifluoroethanol and acetic acid to the $N$-nitrosoamide species gave the desired oxidatively deaminated Kdn thioglycoside donor $\mathbf{1 5}$ in an overall $38 \%$ yield. ${ }^{28}$

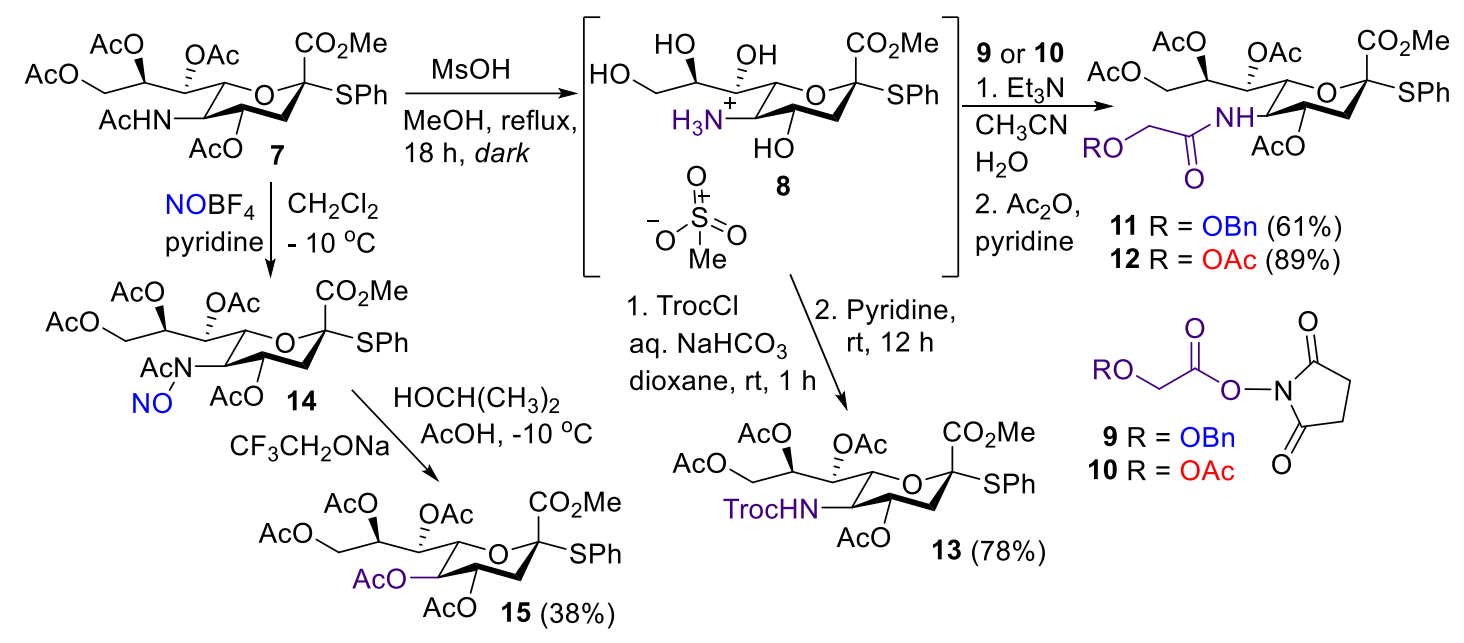

Scheme 2: Synthesis of acetyl and benzyl $N$-glycolyl, $N$-Troc, and Kdn thioglycoside derivatives

With our C-5 derivatised neuraminic acid thioglycosides in hand, we began our glycosylation studies towards the desired 4-methylumbelliferyl $\alpha$-glycosides. Compelling conformational analysis of the glycerol side chain conformation of sialic derivatives (e.g. natural Neu5Ac adopts a gauche-gauche conformation at C-6-C-7 bond) by the Crich group ${ }^{29,30}$ suggested that all four C-5 modified Neu5R umbelliferyl glycosides could be stereoselectively accessed using the same methodology. Thus, control glycosylation reactions between donor 7 and our 4-mu acceptor 16 was carried out using a range of commonly utilised thiophilic promoters to determine their stereoselectivity (Table 1). ${ }^{31-33}$

Table 1: Test glycosylation reactions

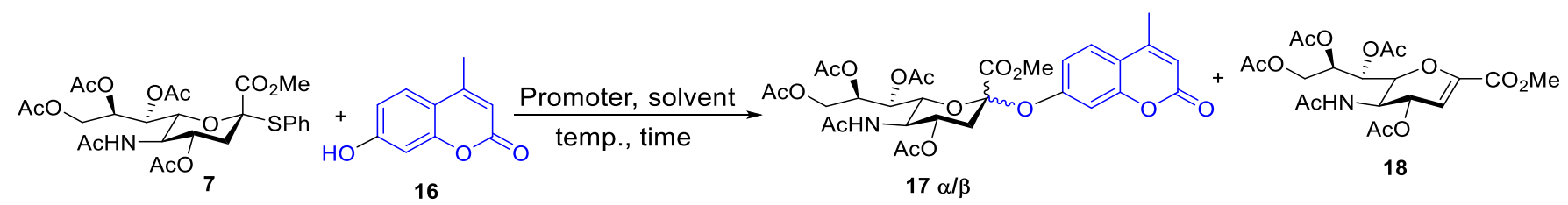

\begin{tabular}{|c|c|c|c|c|c|c|}
\hline Entry & Promoter & Solvent & Temp. & Time & $\begin{array}{c}\text { Product \& } \\
\text { Anomeric ratio }^{\boldsymbol{a}}\end{array}$ & ${\text { Yield of } \mathbf{1 7}^{\boldsymbol{b}}}$ \\
\hline 1 & $\mathrm{NIS} / \mathrm{TfOH}$ & $\mathrm{CH}_{2} \mathrm{Cl}_{2}$ & $\mathrm{rt}$ & $12 \mathrm{~h}$ & Elimination (18), & $18 \%$ \\
\hline
\end{tabular}




\begin{tabular}{|c|c|c|c|c|c|c|}
\hline & & & & & $\begin{array}{c}\text { hydrolysis and } 17 \\
\qquad \alpha / \beta=1: 2.2\end{array}$ & \\
\hline 2 & NIS/TfOH & $\mathrm{CH}_{2} \mathrm{Cl}_{2}$ & $-40^{\circ} \mathrm{C}$ & $12 \mathrm{~h}$ & $18 \& 17 \alpha / \beta=1: 1.6$ & $46 \%$ \\
\hline 3 & NIS/TfOH & $\mathrm{CH}_{2} \mathrm{Cl}_{2}$ & $-78^{\circ} \mathrm{C}$ & $24 \mathrm{~h}$ & $17 \alpha / \beta=1.3: 1$ & $68 \%$ \\
\hline 4 & DMTST & $\mathrm{CH}_{2} \mathrm{Cl}_{2}$ & $0^{\circ} \mathrm{C}$ & $16 \mathrm{~h}$ & $18 \&$ trace of $17 \alpha / \beta$ & - \\
\hline 5 & NIS/AgOTf & $\mathrm{CH}_{2} \mathrm{Cl}_{2}$ & $\begin{array}{c}-40^{\circ} \mathrm{C} \rightarrow \\
\mathrm{rt}\end{array}$ & $12 \mathrm{~h}$ & $\begin{array}{c}18, \text { hydrolysis } \& \\
17 \alpha / \beta=1.7: 1\end{array}$ & $72 \%$ \\
\hline 6 & NIS/AgOTf & $\mathrm{CH}_{2} \mathrm{Cl}_{2}: \mathrm{CH}_{3} \mathrm{CN}$ & $-78^{\circ} \mathrm{C}$ & $16 \mathrm{~h}$ & $17 \alpha / \beta=8.3: 1$ & $87 \%$ \\
\hline 7 & NIS/AgOTf/TBAI & $\mathrm{CH}_{2} \mathrm{Cl}_{2}: \mathrm{CH}_{3} \mathrm{CN}$ & $-78^{\circ} \mathrm{C}$ & $16 \mathrm{~h}$ & $17 \alpha$ & $91 \%, \alpha$ only \\
\hline
\end{tabular}

${ }^{a}$ Determined by ${ }^{1} \mathrm{H}$ NMR analysis of the crude reaction mixture. ${ }^{b}$ Isolated yields

We began our studies with the widely used thiophilic promoter system of $N$-iodosuccinimide (NIS) and triflic acid ( $\mathrm{TfOH}$ ) in $\mathrm{CH}_{2} \mathrm{Cl}_{2}$. Unsurprisingly, at ambient room temperature (typically $20^{\circ} \mathrm{C}$ ), large quantities of the competing glycal side product 18 was observed in addition to the hydrolysed donor; $18 \%$ of $17 \alpha / \beta$ in an anomeric mixture of 1:2.2 $(\alpha / \beta)$ was also recorded (Entry 1$).{ }^{34}$ Similar stereochemical results were observed when the temperature was decreased to $-40{ }^{\circ} \mathrm{C}$ (Entry 2). The anomers were quite difficult to separate by column chromatography as their retention times on silica gel are very similar. This gave us an increased impetus to develop a more stereoselective protocol. Lowering the reaction temperature to -78 ${ }^{\circ} \mathrm{C}$ decreased the amount of glycal observed - unfortunately negligible $\alpha$-selectivity (Entry 3 ) was detected. Changing the promotor to dimethyl(methylthio)sulfonium trifluoromethanesulfonate (DMTST, Entry 4), resulted in the formation of the glycal side product (18) with only trace quantities of $17 \alpha$ observable by NMR. However, activating the glycosylation reaction using NIS/AgOTf at $-40{ }^{\circ} \mathrm{C}$ gave more promising results (entry 5) with a respectable yield of $72 \%$ and a slight preference for the $\alpha$-anomer $17 \alpha$. Expanding on these favourable conditions, introduction of acetonitrile $\left(\mathrm{CH}_{3} \mathrm{CN}\right)$ as an additive solvent increased the observed $\alpha$-selectivity drastically $(\alpha / \beta=8.3: 1)$ in addition to a higher isolated yield (Entry 6). ${ }^{35,36}$ Interestingly, additive tetra- $N$-butylammonium iodide (TBAI) ( 0.8 eq) in conjunction with our improved reaction conditions of NIS/AgOTf in the presence of $\mathrm{CH}_{3} \mathrm{CN}$ furnished complete $\alpha$-selectivity with an excellent yield of $91 \%$ (Entry 8). The synergistic effects of the in situ generated glycosyl iodide and probable subsequent displacement of the less stable $\alpha$ iodide $\left(\mathbf{1 9}_{\mathrm{eq}}\right)$ gives $\beta$ nitrilium ion $\mathbf{2 0}_{\mathrm{ax}}$, which would undergo nucleophilic substitution to give the sole $\alpha$ anomer $\mathbf{1 7} \alpha$ (See SI for plausible mechanism). The addition of TBAI to our reaction mixture was inspired by seminal work on glycosyl iodides in the research group of Grevay-Hague. ${ }^{37-39}$ However, to the best of our knowledge, the anomeric selectivity of sialic acids was not investigated in these studies. 
Table 2: Optimised conditions for glycosylation of C-5 functionalised Sialic acid derivatives

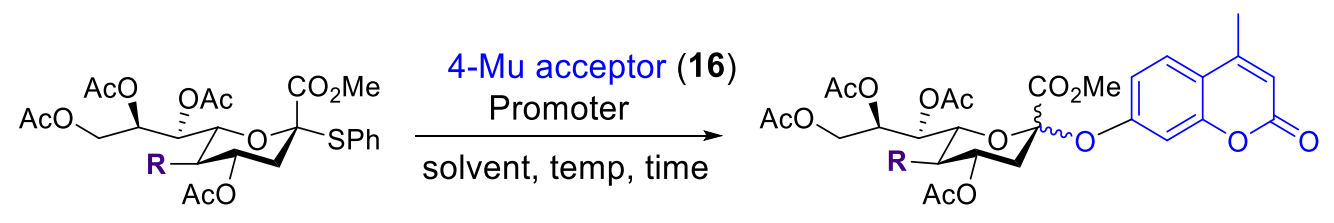

\begin{tabular}{|c|c|c|c|c|c|c|}
\hline $\mathbf{R}$ & Promoter & Solvents & Temp. & Time & $\begin{array}{c}\text { Product \& } \\
\text { Anomeric } \\
\text { ratio }^{a}\end{array}$ & $\begin{array}{l}\text { Yield of } \alpha- \\
\text { anomer }^{b}\end{array}$ \\
\hline $\mathrm{NH}(\mathrm{BnGc}), 11$ & NIS/AgOTf/TBAI & $\mathrm{CH}_{2} \mathrm{Cl}_{2}: \mathrm{CH}_{3} \mathrm{CN}(1: 1)$ & $-78^{\circ} \mathrm{C}$ & $16 \mathrm{~h}$ & $21 \alpha$ only & $89 \%$ \\
\hline $\begin{array}{c}\mathrm{NH}(\mathrm{AcGc}) \\
12\end{array}$ & NIS/AgOTf/TBAI & $\mathrm{CH}_{2} \mathrm{Cl}_{2}: \mathrm{CH}_{3} \mathrm{CN}(1: 1)$ & $-78^{\circ} \mathrm{C}$ & $24 \mathrm{~h}$ & $\begin{array}{c}22 \alpha / \beta \\
4.3: 1\end{array}$ & $72 \%$ \\
\hline NHTroc, 13 & NIS/AgOTf/TBAI & $\mathrm{CH}_{2} \mathrm{Cl}_{2}: \mathrm{CH}_{3} \mathrm{CN}(1: 1)$ & $-78^{\circ} \mathrm{C}$ & $12 \mathrm{~h}$ & $\begin{array}{c}23 \alpha / \beta \\
19: 1\end{array}$ & $75 \%$ \\
\hline OAC, 15 & NIS/AgOTf/TBAI & $\mathrm{CH}_{2} \mathrm{Cl}_{2}: \mathrm{CH}_{3} \mathrm{CN}(1: 1)$ & $-78^{\circ} \mathrm{C}$ & $24 \mathrm{~h}$ & $24 \alpha$ only & $67 \%$ \\
\hline
\end{tabular}

${ }^{a}$ Determined by ${ }^{1} \mathrm{H}$ NMR analysis of the crude reaction mixture. ${ }^{b}$ Isolated yields

Thereafter, we applied the developed $\alpha$-selective glycosylation protocol to the other $\mathrm{C}-5$ functionalised sialic acid donors (Table 2). In all cases, high to excellent diastereoselectivity towards the $\alpha$ anomer was observed proving the optimised glycosylation conditions to be quite general (as predicted). Complete $\alpha$ selectivity and excellent yield $(89 \%, \mathbf{2 1} \alpha)$ was observed with the benzylated Neu5Gc(Bn) donor 11 (Entry 1 ), while good $\alpha$-selectivity ( $\alpha / \beta=4.3: 1$ ) was obtained with the acetylated Neu5Gc donor 12 (Entry 2). The isolated yield of the $\alpha$-anomer product $\mathbf{2 2} \alpha$ was lower (72\%) than its benzylated counterpart, however, in contrast to the Neu5Ac analogue, chromatographic separation of the anomers was not an issue. For the Troc-protected donor $\mathbf{1 3}$, an $\alpha / \beta$ ratio of $19: 1$ of product $\mathbf{2 3} \alpha$ was obtained (Entry 3 ), affording a $75 \%$ yield of the $\alpha$-anomer $\mathbf{2 3} \alpha$ after silica gel column chromatography. Complete $\alpha$-selectivity was obtained for the acetyl protected Kdn glycosyl donor 15 (Entry 4), giving $\mathbf{2 4 \alpha}$ in $67 \%$ isolated yield. All reactions were performed on gram scale $(1-4 \mathrm{~g})$.

Having developed a robust protocol to stereoselectively prepare fluorogenic sialic acid $\alpha$-glycosides, we began our studies towards the corresponding $\beta$-configured 4-methylumbelliferyl glycosides. To determine the feasibility of the diastereoselective glycal addition reaction previously developed in our laboratory, ${ }^{22}$ we carried out an initial test reaction with trityl protected per-benzylated Neu5Ac glycal (25). Treatment of 25 with $\mathrm{Phl}(\mathrm{OAc})_{2}$, molecular iodine and 4-Mu acceptor $\mathbf{1 6}$ gave the desired $\beta$ anomer $\mathbf{2 6}$ in $95 \%$ selectivity $(\alpha / \beta=1: 19)$. Importantly, since in enzyme reactions even small contaminations of the wrong anomer can give false positives, it was found that the 3-iodo anomers were easily separated by silica gel column chromatography. The anomeric configuration was determined by measuring ${ }^{3} \mathrm{~J}_{\mathrm{C}-\mathrm{ax}, \mathrm{H}-3}$ coupling constant of a selectively decoupled coupled ${ }^{13} \mathrm{C}$ NMR experiment. Additionally, the relative anomeric ratio was measured by integrating the $\mathrm{H}$-3eq proton after reduction of the iodo species with triphenyl tin hydride $\left(\mathrm{Bu}_{3} \mathrm{SnH}\right)$ (Scheme 4). ${ }^{40}$ Degassing the reaction mixture via 'freeze-pump-thaw' method was critical for the successful reduction of the iodide species in this reaction. 


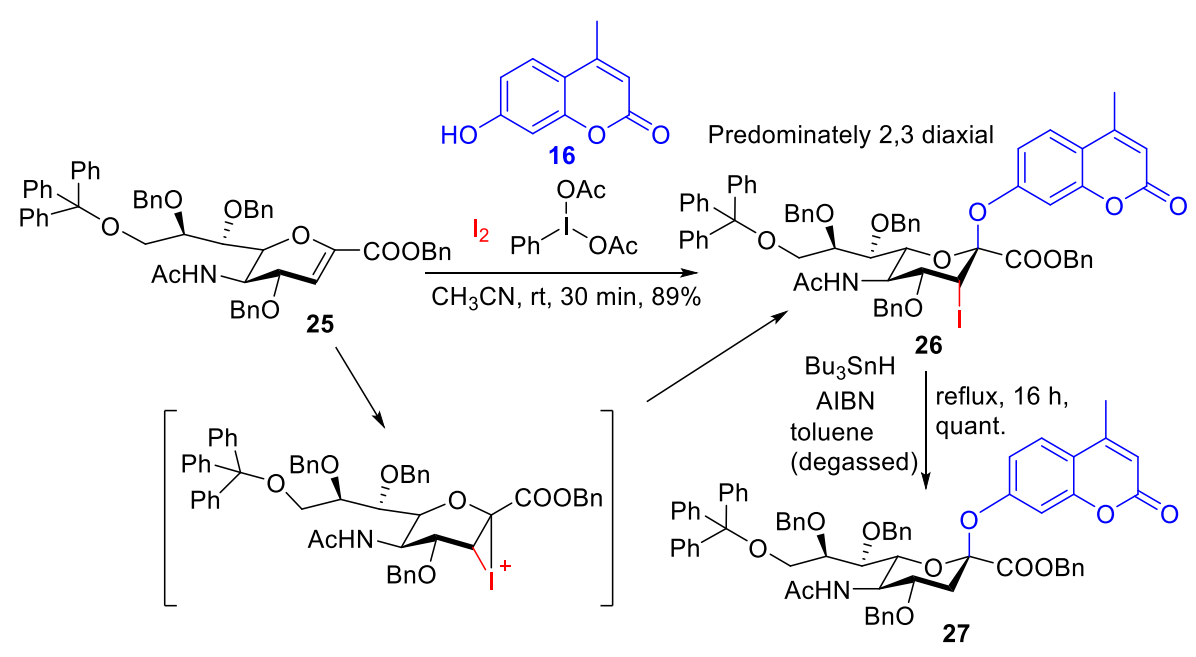

Scheme 4: Diastereoselective addition of $\mathbf{1 6}$ to 25 to furnish 27

This methodology was extended to the remaining C-5 functionalised sialic acid derivatives. Their respective acetylated glycals, 28-30, were easily accessed from the previously prepared thioglycosides $\mathbf{1 2}$, 13, and 15. The sialyl thioglycosides were initially converted into the corresponding bromides and in situ elimination of the resulting bromides by addition of $\mathrm{Et}_{3} \mathrm{~N}$ furnished our desired 2,3-anhydro derivatives 28- 30 in yields ranging from 85-96\% (See SI for synthesis of glycals). Glycal formation was confirmed by high resolution mass spectrometry and by the presence of the diagnostic alkene $\mathrm{H}-3$ proton peaks in ${ }^{1} \mathrm{H}$ NMR spectra at around $5.98 \mathrm{ppm}$. With the $\mathrm{C}-5$ derivatised glycals in hand, their conversion into the desired $\beta$ analogues was investigated (Scheme 5). Accordingly, the acetylated form of Neu5Gc (28) was treated with our optimised reaction conditions of $\mathrm{PhI}(\mathrm{OAc})_{2}$ and $\mathrm{I}_{2}$ in a mixture of acetonitrile and $\mathrm{CH}_{2} \mathrm{Cl}_{2}$ at room temperature. Excess equivalents of 4-Mu (16, 5 eq) were necessary for higher yields. Completion of the reaction (between 20 and $30 \mathrm{~min}$ ) was monitored by TLC and rapidly worked up. It should be noted that leaving the reaction on for longer than required results in a complex mixture. A relatively low $\alpha / \beta-$ ratio of 1:3 was observed. After anomer separation followed by 'traceless' reduction of the iodide functionality using $\mathrm{Bu}_{3} \mathrm{SnH} / \mathrm{AIBN}$, the $\beta-4-\mathrm{Mu}-\mathrm{Neu} 5 \mathrm{Gc}$ derivative $\mathbf{2 2} \beta$ was isolated in a $68 \%$ yield over the two steps.

The NeuTroc (29) and Kdn (30) glycals were also subjected to the same glycosylation conditions and the desired $\beta$ 4-methylumbelliferyl glycosides 23 and 24 were isolated in $71 \%$ and $62 \%$ yield respectively, following tributyl tin hydride mediated reduction (Scheme 5 ). The observed relatively lower $\beta$ selectivity for $28(1: 3, \alpha: \beta), 29(1: 2.7, \alpha: \beta)$, and $30(1: 3.5, \alpha: \beta)$ might be attributed to our chosen ester protecting groups, but all the diastereomeric mixtures were easily separated before the tin hydride reduction. Consequently, the decrease in stereoselectivity is offset by the ability to generate large quantities of pure $\beta$ 4-methylumbelliferyl sialic glycosides following chromatographic separation of the 3-iodo species. It should be noted that no previous syntheses of the unnatural $\beta$ umbelliferyl sialic glycosides for Kdn, Neu, and Neu5Gc have been reported in literature. 


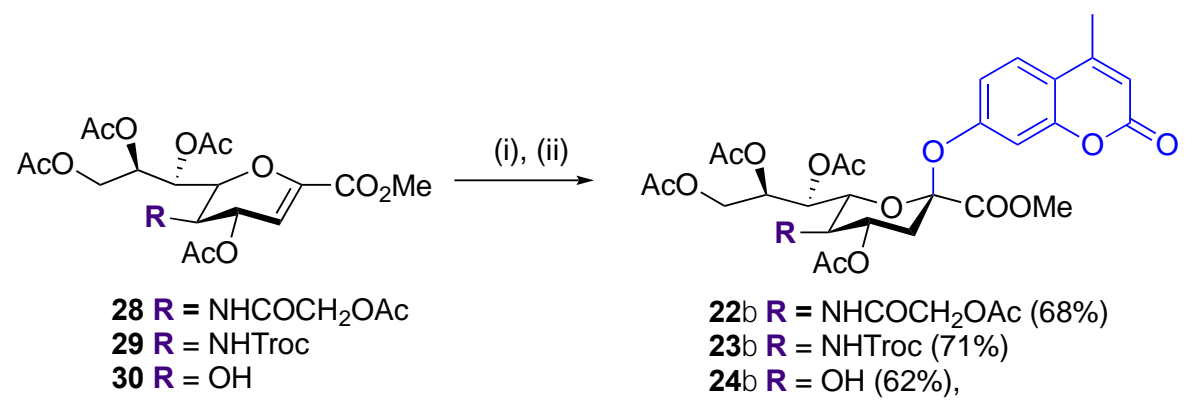

Scheme 5: Reagents \& conditions: (i) Phl(OAC) $)_{2} \mathrm{I}_{2}, 16, \mathrm{CH}_{3} \mathrm{CN}: \mathrm{CH}_{2} \mathrm{Cl}_{2}, \mathrm{rt}, 20$ - 30 min; (ii) $\mathrm{Bu}_{3} \mathrm{SnH}, \mathrm{AlBN}$, degassed toluene, reflux, $18 \mathrm{~h}$.

\section{Conclusions}

In summary, a library of C-5 derivatised 4-methylumbelliferone sialic acid derivatives (Neu, Neu5Ac, Neu5Gc, Kdn) were synthesised in high yields from $N$-acetylneuraminic acid. The $\alpha$ anomers were stereoselectively accessed by synergistic acetonitrile-mediated solvent control, aided by in situ generated glycosyl iodides utilising additive TBAl. Our novel $\alpha$-sialylation approach combines concepts of in situ anomerisation method introduced by Lemieux with contemporary reagent-controlled glycosylation techniques. ${ }^{41-43}$ Excellent to good yields and $\alpha$-stereoselectivity was observed for all the C-5 functionalised sialic derivatives; consistent with the belief that the glycerol side chain (conserved for all of our analogues in this case) conformation of nonulosonic acids can determine the stereochemical outcome during glycosylation reactions. ${ }^{29,30,44}$ Similarly, the $\beta$-anomers were selectively synthesised via a preferential diastereoselective addition reaction to our C-5 derivatised neuraminic acid glycal analogues. Both anomer-oriented synthetic pathways allow for the gram scale stereoselective synthesis of the desired C-5 modified neuraminic acid derivatives for further chemoenzymatic studies. This methodology could also be further extended to bacterial nonulosonic acids hydrolases (which can be both axial and equatorial in anomeric configuration). It is our hope that the synthesis of these derivatives will allow for the fluorometric quantification of the enzymatic activity and substrate specificity of known sialidases, and the detection of novel sialidases found in nature.

\section{References}


(1) Schauer, R. Sialic Acids as Regulators of Molecular and Cellular Interactions. Current Opinion in Structural Biology 2009, 19 (5), 507-514. https://doi.org/10.1016/j.sbi.2009.06.003.

(2) Varki, A.; Gagneux, P. Multifarious Roles of Sialic Acids in Immunity. Annals of the New York Academy of Sciences 2012, 1253 (1), 16-36. https://doi.org/10.1111/j.17496632.2012.06517.x.

(3) Severi, E.; Hood, D. W.; Thomas, G. H. Sialic Acid Utilization by Bacterial Pathogens. Microbiology. 2007, pp 2817-2822. https://doi.org/10.1099/mic.0.2007/009480-0.

(4) Newstead, S. L.; Potter, J. A.; Wilson, J. C.; Xu, G.; Chien, C. H.; Watts, A. G.; Withers, S. G.; Taylor, G. L. The Structure of Clostridium Perfringens Nanl Sialidase and Its Catalytic Intermediates. Journal of Biological Chemistry 2008, 283 (14), 9080-9088. https://doi.org/10.1074/jbc.M710247200.

(5) Varki, A.; Cummings, R. D.; Esko, J. D.; Stanley, P.; Hart, G. W.; Aebi, M.; Darvill, A. G.; Kinoshita, T.; Packer, N. H.; Prestegard, J. H.; Schnaar, R. L.; Seeberger, P. H. Essentials of Glycobiology, Third Edition; 2017.

(6) Parker, R. B.; Kohler, J. J. Regulation of Intracellular Signaling by Extracellular Glycan Remodeling. ACS Chemical Biology. 2010, pp 35-46. https://doi.org/10.1021/cb9002514.

(7) Saito, M.; Yu, R. K. Biochemistry and Function of Sialidases. In Biology of the Sialic Acids; 1995; pp 261-313. https://doi.org/10.1007/978-1-4757-9504-2_8.

(8) Mehr, K.; Withers, S. G. Mechanisms of the Sialidase and Trans-Sialidase Activities of Bacterial Sialyltransferases from Glycosyltransferase Family 80. Glycobiology 2016, 26 (4), 353-359. https://doi.org/10.1093/glycob/cwv105.

(9) Hinek, A.; Pshezhetsky, A. V.; Von Itzstein, M.; Starcher, B. Lysosomal Sialidase (Neuraminidase-1) Is Targeted to the Cell Surface in a Multiprotein Complex That Facilitates Elastic Fiber Assembly. Journal of Biological Chemistry 2006. https://doi.org/10.1074/jbc.M508736200.

(10) Yamanami, H.; Shiozaki, K.; Wada, T.; Yamaguchi, K.; Uemura, T.; Kakugawa, Y.; Hujiya, T.; Miyagi, T. Down-Regulation of Sialidase NEU4 May Contribute to Invasive Properties of Human Colon Cancers. Cancer Science 2007. https://doi.org/10.1111/j.13497006.2007.00403.x.

(11) Miyagi, T.; Yamaguchi, K. Mammalian Sialidases: Physiological and Pathological Roles in Cellular Functions. Glycobiology. 2012. https://doi.org/10.1093/glycob/cws057.

(12) Tringali, C.; Lupo, B.; Anastasia, L.; Papini, N.; Monti, E.; Bresciani, R.; Tettamanti, G.; Venerando, B. Expression of Sialidase Neu2 in Leukemic K562 Cells Induces Apoptosis by Impairing Bcr-Abl/Src Kinases Signaling. Journal of Biological Chemistry 2007. https://doi.org/10.1074/jbc.M700406200.

(13) Gray, M. A.; Stanczak, M. A.; Mantuano, N. R.; Xiao, H.; Pijnenborg, J. F. A.; Malaker, S. A.; Miller, C. L.; Weidenbacher, P. A.; Tanzo, J. T.; Ahn, G.; Woods, E. C.; Läubli, H.; Bertozzi, C. R. Targeted Glycan Degradation Potentiates the Anticancer Immune Response in Vivo. Nature Chemical Biology 2020. https://doi.org/10.1038/s41589-020-0622-x. 
(14) Bhavanandan, V. P.; Yeh, A. K.; Carubelli, R. Neuraminidase Assay Utilizing SialylOligosaccharide Substrates with Tritium-Labeled Aglycone. Analytical Biochemistry 1975, 69 (2), 385-394. https://doi.org/10.1016/0003-2697(75)90140-2.

(15) Schwarzmann, G. A Simple and Novel Method for Tritium Labeling of Gangliosides and Other Sphingolipids. Biochimica et Biophysica Acta (BBA)/Lipids and Lipid Metabolism 1978, 529 (1), 106-114. https://doi.org/10.1016/0005-2760(78)90108-X.

(16) Zbiral, E.; Brandstetter, H. H.; Christian, R.; Schauere, R. Structural Variations of NAcetylneuraminic Acid, 7. Synthesis of the C-7-, C-8-, and C-7,8-Side Chain Epimers of 2Deoxy-2,3-didehydro-N-acetylneuraminic Acid and Their Behaviour Towards Sialidase from Vibrio Cholerae. Liebigs Annalen der Chemie 1987, 1987 (9), 781-786. https://doi.org/10.1002/jlac.198719870828.

(17) Hunter, C. D.; Porter, E. M.; Cairo, C. W. Human Neuraminidases Have Reduced Activity towards Modified Sialic Acids on Glycoproteins. Carbohydrate Research 2020, 497. https://doi.org/10.1016/j.carres.2020.108139.

(18) Zbiral, E.; Schreiner, E.; Salunkhe, M. M.; Schulz, G.; Kleineidam, R. G.; Schauer, R. Structural Variations of N-Acetylneuraminic Acid, 11, Synthesis of the 4-Methylumbelliferyl $2 \alpha-$ Glycosides of 7-Epi-, 8-Epi-, and 7,8-Bis(Epi)-N-acetylneuraminic Acids, as Well as of 7-Deoxy-, 8-Deoxy-, 9-Deoxy-, and 4,7-Dideoxy-N-acetylneuraminic Acids An. Liebigs Annalen der Chemie 1989, 1989 (6), 519-526. https://doi.org/10.1002/jlac.198919890192.

(19) Kuboki, A.; Sekiguchi, T.; Sugai, T.; Ohta, H. A Facile Access to Aryl $\alpha$-Sialosides: The Combination of a Volatile Amine Base and Acetonitrile in Glycosidation of Sialosyl Chlorides. Synlett 1998, No. 5, 479-482. https://doi.org/10.1055/s-1998-1717.

(20) Zamora, C. Y.; D’Alarcao, M.; Kumar, K. Fluorogenic Sialic Acid Glycosides for Quantification of Sialidase Activity upon Unnatural Substrates. Bioorganic and Medicinal Chemistry Letters 2013, 23 (11), 3406-3410. https://doi.org/10.1016/j.bmcl.2013.03.076.

(21) Baggett, N.; Marsden, B. J. Reinvestigation of the Synthesis of 4-Methylcoumarin-7-YI 5Acetamido-3,5-Dideoxy- $\alpha$-d-Glycero-d-Galacto-2-Nonulopyranosidoni c Acid, a Fluorogenic Substrate for Neuraminidase. Carbohydrate Research 1982, 110 (1), 11-18. https://doi.org/10.1016/0008-6215(82)85022-2.

(22) Hassan, A. A.; Oscarson, S. A General Method for the Divergent Synthesis of C-9 Functionalised Sialic Acid Derivatives. European Journal of Organic Chemistry 2020. https://doi.org/10.1002/ejoc.202001049.

(23) Kanie, O.; Kiso, M.; Hasegawa, A. Glycosylation Using Methylthioglycosides of NAcetylneuraminic Acid and Dimethyl(Methylthio)Sulfonium Triflate. Journal of Carbohydrate Chemistry 1988, 7 (2), 501-506. https://doi.org/10.1080/07328308808058938.

(24) Marra, A.; Sinaÿ, P. Stereoselective Synthesis of 2-Thioglycosides of N-Acetylneuraminic Acid. Carbohydrate Research 1989, 187 (1), 35-42. https://doi.org/10.1016/0008-6215(89)800540.

(25) Sugata, T.; Higuchi, R. A Facile Preparation of the Methyl 2-Tioglycoside of NGlycolyIneuraminic Acid, an Efficient Donor of NeuGc. Tetrahedron Letters 1996, 37 (15), 2613-2614. https://doi.org/10.1016/0040-4039(96)00383-8. 
(26) Schreiner, E.; Zbiral, E. Structural Variations on N-acetylneuraminic Acid, 16. A Convenient Approach to 3-deoxy-D-glycero-D-galacto-nonulosonic Acid (KDN), 5-azido-5-deoxy-KDN and 5-deoxy-KDN, and Their 4-methylumbelliferyl $2 \alpha$-glycosides. Liebigs Annalen der Chemie 1990, 1990 (6), 581-586. https://doi.org/10.1002/jlac.1990199001107.

(27) Shirai, R.; Nakamura, M.; Hara, S.; Takayanagi, H.; Ogura, H. Thermal Rearrangement of NAcetyl-N-Nitrosoneuraminic Acid Derivative: Synthesis of 3-Deoxy-D-Nonulosonic Acid (KDN). Tetrahedron Letters 1988, 29 (35), 4449-4452. https://doi.org/10.1016/S00404039(00)80519-5.

(28) Crich, D.; Navuluri, C. Stereoselective Synthesis of $\alpha$-Keto-Deoxy-D-Glycero-DGalactononulosonic Acid Glycosides by Means of the 4,5-O-Carbonate Protecting Group. Angewandte Chemie - International Edition 2010, 49 (17), 3049-3052. https://doi.org/10.1002/anie.200907178.

(29) Kancharla, P. K.; Crich, D. Influence of Side Chain Conformation and Configuration on Glycosyl Donor Reactivity and Selectivity as Illustrated by Sialic Acid Donors Epimeric at the 7Position. Journal of the American Chemical Society 2013, 135 (50), 18999-19007. https://doi.org/10.1021/ja410683y.

(30) Dhakal, B.; Crich, D. Synthesis and Stereocontrolled Equatorially Selective Glycosylation Reactions of a Pseudaminic Acid Donor: Importance of the Side-Chain Conformation and Regioselective Reduction of Azide Protecting Groups. Journal of the American Chemical Society 2018, 140 (44), 15008-15015. https://doi.org/10.1021/jacs.8b09654.

(31) Demchenko, A.; Stauch, T.; Boons, G. J. Solvent and Other Effects on the Stereoselectivity of Thioglycoside Glycosidations. Synlett 1997, 1997 (7), 818-820. https://doi.org/10.1055/s1997-5762.

(32) Mong, K. K. T.; Nokami, T.; Tran, N. T. T.; Nhi, P. B. Solvent Effect on Glycosylation. In Selective Glycosylation: Synthetic Methods and Catalysts; 2017; pp 59-77. https://doi.org/10.1002/9783527696239.ch3.

(33) Crich, D. Mechanism of a Chemical Glycosylation Reaction. Accounts of Chemical Research 2010, 43 (8), 1144-1153. https://doi.org/10.1021/ar100035r.

(34) Crich, D.; Li, W. O-Sialylation with N-Acetyl-5-N,4-O-Carbonyl-Protected Thiosialoside Donors in Dichloromethane: Facile and Selective Cleavage of the Oxazolidinone Ring. Journal of Organic Chemistry 2007, 72 (7), 2387-2391. https://doi.org/10.1021/jo062431r.

(35) Demchenko, A.; Stauch, T.; Boons, G. J. Solvent and Other Effects on the Stereoselectivity of Thioglycoside Glycosidations. Synlett 1997, 1997 (7), 818-820. https://doi.org/10.1055/s1997-5762.

(36) Mong, K. K. T.; Nokami, T.; Tran, N. T. T.; Nhi, P. B. Solvent Effect on Glycosylation. In Selective Glycosylation: Synthetic Methods and Catalysts; 2017; pp 59-77. https://doi.org/10.1002/9783527696239.ch3.

(37) Hadd, M. J.; Gervay, J. Glycosyl lodides Are Highly Efficient Donors under Neutral Conditions. Carbohydrate Research 1999, 320 (1-2), 61-69. https://doi.org/10.1016/S00086215(99)00146-9. 
(38) Gervay, J.; Nguyen, T. N.; Hadd, M. J. Mechanistic Studies on the Stereoselective Formation of Glycosyl lodides: First Characterization of $\beta$-D-Glycosyliodides. Carbohydrate Research 1997, 300 (2), 119-125. https://doi.org/10.1016/S0008-6215(96)00321-7.

(39) Gervay-Hague, J. Taming the Reactivity of Glycosyl lodides to Achieve Stereoselective Glycosidation. Accounts of Chemical Research 2016, 49 (1), 35-47. https://doi.org/10.1021/acs.accounts.5b00357.

(40) Hori, H.; Nakajima, T.; Nishida, Y.; Ohrui, H.; Meguro, H. A Simple Method to Determine the Anomeric Configuration of Sialic Acid and Its Derivatives by 13C-NMR. Tetrahedron Letters 1988, 29 (48), 6317-6320. https://doi.org/10.1016/S0040-4039(00)82335-7.

(41) Yao, H.; Vu, M. D.; Liu, X. W. Recent Advances in Reagent-Controlled Stereoselective/Stereospecific Glycosylation. Carbohydrate Research 2019. https://doi.org/10.1016/j.carres.2018.10.006.

(42) Ishiwata, A.; Lee, Y. J.; Ito, Y. Recent Advances in Stereoselective Glycosylation through Intramolecular Aglycon Delivery. Organic and Biomolecular Chemistry 2010, 8 (16), 35963608. https://doi.org/10.1039/c004281a.

(43) Lemieux, R. U.; Hayami, J.-I. The Mechanism of the Anomerization of the Tetra- O -Acetyl- D Glucopyranosyl Chlorides . Canadian Journal of Chemistry 1965, 43 (8), 2162-2173. https://doi.org/10.1139/v65-292.

(44) Ngoje, P.; Crich, D. Stereocontrolled Synthesis of the Equatorial Glycosides of 3-Deoxy- d Manno-Oct-2-Ulosonic Acid: Role of Side Chain Conformation. Journal of the American Chemical Society 2020, 142 (17), 7760-7764. https://doi.org/10.1021/jacs.0c03215. 